Logos. Anales del Seminario de Metafísica

ISSN: 1575-6866

https://dx.doi.org/10.5209/asem.65865

\title{
Redimir a Nietzsche (por enésima vez)
}

Mariano Rodríguez ${ }^{1}$

Romero Cuevas, José Manuel, ¿Nietzsche contra Nietzsche? Ensayos de crítica filosófica inmanente. Madrid, Locus Solus, 2016, 244 págs.

No obstante la innegable originalidad de su planteamiento inicial -estaríamos ante un ensayo de "crítica inmanente": nada menos que el de llevar a Nietzsche contra Nietzsche-, se puede decir que esta importante obra del profesor Romero irrumpe en el panorama de los estudios críticos del pensamiento nietzscheano siguiendo una estrategia muy en boga, puesto que en todo momento se enmarcaría en un uso moderno sin duda frecuentado, el de proceder filosóficamente en el terreno de reflexión delimitado por el consabido doble polo, auténtica pinza, de lo epistemológico y lo ético-político. Así que se trata, en definitiva, de aquello que ya promovía las ironías nietzscheanas: de lo que se trata es de buscar la verdad, claro, pero solo con el fin de hacer el bien (entonces «japuesto a que no se encuentra nada!», reponía el filósofo con su "maldad" tan característica). Se trata, en suma, del intento de encontrar en Nietzsche un planteamiento epistemológico serio que por serlo vaya a permitirnos derivaciones ético-políticas no inconvenientes, adecuadas a nuestra sensibilidad, respetables, o sea, progresistas.

Pero justamente eso no lo podríamos encontrar en Nietzsche, un planteamiento crítico y riguroso en una teoría del conocimiento respetable. Todo lo contrario, sus reflexiones en este campo, pese a sus indiscutibles logros, gracias a los que el filósofo habría adquirido un lugar de honor entre los clásicos de la historia de la filosofía, habrán de ser calificadas de ingenuas, filosóficamente naif.

Ya de la parte primera del libro, dedicada a la cuestión ética y estética, podemos deducir que los criterios nietzscheanos para la bondad y la verdad arrancan del radical criterio de la belleza. Porque en el estado estético fundamental, el de la embriaguez, lo que tenemos es que aumenta o se intensifica el sentimiento de poder. Pero esto es lo mismo que definiría "lo bueno", y por supuesto también "lo verdadero", es verdadero todo aquello que aumenta mi sensación de poder. En este punto conviene andarse con cuidado, no vayamos a caer en la manía del eslogan, tan cómoda por descerebrada, y a lo peor dar en decir, con aquel jerarca nazi encargado de la propaganda del régimen, que "es verdadero todo lo que me gusta", declaración que

Universidad Complutense de Madrid 
sin duda consigue llegar al colmo en materia de estupidez humana o infrahumana. El profesor Romero contrasta dos modelos de subjetividad diferentes, en el joven y en el último Nietzsche, desde los dos conceptos distintos y correspondientes de embriaguez. Cuando se lee en este filósofo que «la embriaguez [es] la intensificada sensación de poder; la interna necesidad de hacer de las cosas un reflejo de la propia plenitud y perfección» (KSA, 13.356, 14 [170]), es inevitable llegar a la conclusión de que la concepción nietzscheana del conocimiento se montaría sobre o a partir del modelo de la creación artística, entendiendo la praxis propia del arte como "praxis productora de formas", lo que muy bien subraya el profesor Romero.

Y sin duda hay que aplicar a las elaboraciones filosóficas nietzscheanas su propio criterio de verdad. Solo así haríamos crítica "inmanente". Pero entonces se entiende perfectamente lo que ocurre cuando asoma por vez primera un asunto capital del libro, el del profundo desagrado o disgusto del autor ante los textos de lo que podemos llamar el "Nietzsche negro", textos que, por supuesto todos conocemos y que, por lo general, tratamos de evitar o incluso de preterir, error o falta de honradez en que no quiere caer el autor. Uno de ellos muy citado nos relata la «serie atroz» de las palizas, las violaciones, los asesinatos cometidos por la célebre bestia rubia como otras tantas travesuras contra los que no son sus iguales (GM-I, 11). Para pasar a compararlos inmediatamente, en el caso de este libro, con las consabidas escenas de desatada violencia en La naranja mecánica o con las brutalidades de las tropas de asalto hitlerianas. Se intuye que aquí el gusto moral del profesor Romero, que es el nuestro, tal vez le impide contextualizar de forma correcta este fragmento nietzscheano. Porque si no se lo impidiera habría comprendido que las comparaciones realizadas son absolutamente insostenibles, y que la idea de volcar y desfogar la agresión hacia el exterior del propio círculo social no es ninguna idea arqueológica descabellada sino todo lo contrario, está por lo demás presente en los análisis aplicados de Freud, en este sentido libre de toda sospecha. Hablamos de moralina cuando se esgrime el argumento de la moral sin que venga a cuento, y es que la moralina sería siempre impertinente, poniendo en la espalda del adversario la necesidad de demostrar que no es un malvado, igual que Sócrates obligaba a sus interlocutores a demostrar que no eran estúpidos. En suma, la moral como arma de combate o incluso como la más potente de todas las armas de combate. Sin duda, el hombre de Rousseau es mucho más consolador que el de Hobbes, dónde va a parar, el problema está en su más que problemática objetividad histórica. Pensar en el hombre de Rousseau, comparativamente hablando, aumenta la sensación de poder (la "felicidad") de la mayoría, y de ahí se concluye que es verdadero decir que la maldad humana proviene de instituciones injustas o de un sistema de producción verdaderamente criminal que por tanto habría que destruir y reconstruir. Con ello, de propina, se obtiene nada menos que un sentido para la existencia, una razón para vivir sintiéndonos buenos y justos. No se puede pedir más.

Pero ya se sabe que Nietzsche no nos entrega ninguna moral universalista, más aún, tampoco lo pretende, sino todo lo contario, lo que quiere es que prescindamos de todo uni-forme para que cada uno se invente su propio código de conducta. No es Kant lo mismo que nuestro filósofo, ya se sabe, pero eso no le condena a tener que pensar toda relación humana como esencialmente "depredativa". No ser como Kant no es lo mismo que ser un monstruo, por mucho que Nietzsche fuese siempre un amigo de lo monstruoso o informe. En su vida y en su obra claro que caben la benevolencia, la amistad, incluso una clase de amor que no es el amor antinatural 
del cristianismo. Nietzsche piensa las relaciones humanas según corresponde a la naturalidad de las mismas: amor a quien nos hace el bien, buena voluntad para quien podemos comprender. Lo que se nos hace francamente chocante, alarmante incluso, es que se nos mande amar a todos los seres humanos, sobre todo a nuestros enemigos, con el curioso argumento de que eso sí que tendría mérito. Este mandato, sencillamente, no lo podemos entender. Pero tampoco Freud lo podía entender, y nadie dijo que por eso fuese un amigo de los nazis.

Seguramente la aportación original de esta obra se lleva a cabo gracias a que su autor se sitúa, para ofrecernos un panorama crítico del pensamiento nietzscheano, en el plano gnoseológico de su teoría de la verdad. El mismo Romero lo había venido haciendo en espléndidas investigaciones anteriores, y otros estudiosos, dentro y fuera de nuestro país, habían asimismo subrayado la importancia de esta temática tan embrollada. Sin duda que la filosofía de Nietzsche asume una experiencia de la verdad que podemos considerar "nueva", por lo menos relativamente, y sin duda revolucionaria. En definitiva, la experiencia de la «muerte de Dios» enmarca el sentido en que debemos entender siempre este pensamiento. $\mathrm{Y}$ esa experiencia va a vertebrar, de nuevo, nuestra concepción de la verdad misma. En su momento, la influyente obra de Granier distinguió entre verdad originaria, verdad pragmática y pseudo-verdad de la Metafísica. Enmendándole la plana al estudioso francés, el profesor Romero nos referirá, en el terreno que denomina "metafísico-existencial", empleando un lenguaje a mi modo de ver algo sospechoso, a una verdad pragmática constituida desde los "intereses de la vida", pero también a una "verdad en sí del ser" y a una verdad establecida por la ciencia.

Si empezamos por centrarnos en esta última, se defiende en la obra que, tanto para el primer Nietzsche como para el último, la praxis de la ciencia sería "cosificadora" de lo real, y por consiguiente nos avecindaría a la pretendida "verdad metafísica". Desde mi punto de vista, es cierto que Nietzsche cuestiona una práctica científica que cree todavía en el valor divino de la verdad, es decir, una ciencia que no se habría liberado aún de la mentalidad metafísica. Pero frente a esto, la ciencia tal y como Nietzsche la entiende y la promueve debe ser tomada como la humanización más radical del mundo, como la traducción de lo inhumano en humano promovida desde los intereses de la vida de la especie. Y en este aspecto la verdad de la ciencia es también verdad pragmática, o mejor, la verdad pragmática llevada hasta sus últimas consecuencias. Lo que se necesita es que el científico lo consiga entender así y no de la otra manera tradicional, metafísica.

Pero el problema mayor surge en el momento en que el profesor Romero pasa a criticar la que llama "verdad en sí del ser" en una presunta versión nietzscheana, sencillamente porque, sin duda, no habría manera de entender esta chocante expresión de la verdad ontológica en un sentido verdaderamente nietzscheano. Para comenzar tengo que poner reparos al uso del lenguaje que aquí se despliega, porque insisto en que, a mi juicio, no se puede entender la verdad originaria o dionisíaca o trágica como "verdad en sí del ser", como tampoco conviene hablar en este punto de la relación entre "la criatura finita y el ser", por lo menos si se quiere permanecer en contacto con la idea nietzscheana de las cosas. Toda esta terminología es lamentablemente tradicional, y, por otra parte, lo de la "criatura finita" sí que tiene un aroma de 
sacristía poco soportable. Como se sabe, busca Nietzsche ante todo eliminar de las venas del filósofo toda gota de sangre de teólogo, incluida, pienso yo, la del teólogo "de la liberación". "La relación de la criatura finita con la verdad en sí del ser", esto es algo que resulta en una figura tradicional tan metafísica que hoy haría ilegible cualquier libro de filosofía en que apareciera; al menos para mí, que soy lector de larga experiencia juvenil en la escolástica más decadente y amanerada.

La intuición o revelación trágica constituye a Nietzsche como filósofo, y como el filósofo que es. La intuición o revelación trágica la podemos entender según la palabra inmemorial de Heráclito de Éfeso, como sabiduría del devenir y de la guerra de todas las cosas, o tal vez mejor, como el descubrimiento del absoluto sinsentido de lo real, que no nos envía ningún mensaje, en su cruel indiferencia, si queremos seguir la línea de la caracterización de Rosset. El mundo no tiene por qué ajustarse a las categorías de nuestra razón, como tampoco a las exigencias de nuestra sensibilidad moral. El mundo es, para Nietzsche, el caos o caosmos de la voluntad de poder, el monstruo del eterno crear y destruir que siempre retornan necesariamente. Ahora bien, supone una confusión entender esta verdad trágica como el resultado del acceso cognitivo a la esencia del "ser" tal y como es en sí mismo, prescindiendo de su relación con nosotros. No se puede decir con sentido que Nietzsche afirme, evidentemente entonces sin ninguna justificación aducible por su parte, un ser "parmenídeo", un Uno cualquiera, porque de lo contrario semejante ser parmenídeo habría de consistir, propiamente, en el no-ser, o sea, en el devenir heraclíteo, lo cual carece por completo de sentido. Como tampoco se puede presuponer, como si tal cosa, la línea cosa en sí (Kant) $\rightarrow$ voluntad (Schopenhauer) $\rightarrow$ voluntad de poder (Nietzsche) como mera acumulación de lo mismo, aunque tal vez sí como remedo o parodia del lenguaje metafísico. Porque todo esto implicaría no haber entendido en absoluto la transformación nietzscheana de la verdad en el sentido performativo de un hacer-verdad. La hipótesis de la voluntad de poder es una interpretación sabedora de serlo que va hasta el final en la operación humanizadora de lo real: no es solo que proyectemos el sentido humano, sino que todo sentido sería voluntad de poder. Bien es cierto que esta, a mi parecer, mala comprensión de Romero, en la que según él le acompañarían Quesada y Conill, estaría parcialmente justificada, por cuanto el filósofo alemán juega continuamente a la parodia del concepto de verdad, haciendo como si estuviera teniendo en cuenta en todo momento la tradicional idea de la correspondencia o adecuación. "Lo que hay" es la fuerza que pone las interpretaciones, es decir, que pone la unidad y las identidades, pero por eso mismo toda unidad y toda identidad serían ficticias o "falsas" por definición, en comparación con esa fuerza, pero esto se dice en el sentido paródico de la verdad como adecuación. No se trata, con Nietzsche, de proyectar según el modo idealista el sentido sobre ningún en sí desprovisto de sentido, sino del descubrimiento de la physis como fuerza creadora, dionisíaca. Por eso, cuando se contrapone el presunto idealismo nietzscheano, como relación meramente contemplativa de sujeto y objeto, a la idea marxiana de trabajo o praxis transformadora del medio de la especie humana, o bien se está procediendo a criticar a Nietzsche de un modo nada inmanente, o bien se pasa por alto que la misma categoría de praxis puede ser entendida también desde el modelo de la praxis artística de la producción de formas, que el mismo Romero por otra parte sabe poner de relieve en Nietzsche perfectamente.

De manera que la verdad originaria o dionisíaca propia de la revelación trágica no puede en absoluto entenderse como verdad del ser. No es la cosa en sí 
contradictoriamente revelada, sino la revelación de que la noción misma de cosa en sí es inutilizable porque es una noción vacía de todo sentido, "digna de una carcajada homérica". La verdad dionisíaca es la del conocimiento de que no hay verdad del ser, de que no hay "ser". Nietzsche es radicalmente contrario al ser, como todos sabemos. Contrario en definitiva a Parménides, pensador arcaico desde cuya época "pesa sobre nuestra cultura, como una losa, la funesta separación de alma y cuerpo". Y, por otra parte, nos cuenta el filósofo alemán que fue leyendo a Tucídides como se acabó de liberar por fin de Platón. Pero esto no significa en absoluto que el pensamiento nietzscheano, malinterpretado como mera inversión de Parménides/ Platón, permanezca en el ámbito de la Metafísica como su remate o consumación por inversión. No es el devenir un tipo de ser, no es la revelación trágica intuición elitista, e injustificable para la razón (común), de la verdad ontológica, creo que en eso hay que estar de acuerdo. Porque la experiencia nietzscheana de la verdad ya no es metafísica sino performativa. Leer a Tucídides nos lleva a la hipótesis de la voluntad de poder, lógicamente, pero esto no es como llevarnos a la "verdad del ser en sí mismo" porque si no seguiríamos con Platón.

Además, pero por lo mismo, es prueba de incomprensión de esta nueva experiencia de la verdad objetar a Nietzsche que en ningún lugar justifica o da razones de su fe dionisíaca. Esto sin contar con que, incluso sin salir del ámbito de lo tradicional, sabemos de sobra que del 'primer principio' de un pensamiento nadie puede dar cuenta, mucho menos el pensador que por primera vez lo piensa. Se trata de la intuición originaria que convierte en tal a un filósofo, nada más y nada menos. Pensemos en Spinoza, en Hume, en Schopenhauer...para limitarnos a los modernos.

Nos relata Safranski que, antes de darle una segunda lectura a la obra capital de Schopenhauer, Nietzsche leyó con entusiasmo la de Lange. Y eso fue lo que le habría permitido criticar después a Schopenhauer y así empezar a distanciarse filosóficamente de él: "No se puede, advierte [Nietzsche], hacer ninguna afirmación sobre la desconocida 'cosa-en-sí', y ni siquiera se puede decir que todos los predicados del mundo fenoménico, como el espacio, el tiempo y la causalidad, han de eliminarse de esta 'cosa en sí'. Lo inaccesible al conocimiento no puede interpretarse como imagen negativa de lo cognoscitivo". . En Sobre verdad y mentira en sentido extramoral, delineando los mecanismos lingüísticos de metaforización, ya se sabe que nuestro filósofo va a clausurar definitivamente la posibilidad de cualquier acceso idealista o romántico a las madres del ser. Pero esta crítica nietzscheana es a todas luces compatible con el mantenimiento de la idea de que el mundo es "impulso y tendencia oscura", "una realidad dinámica y carente de sentido, si la medimos según el patrón de nuestra razón"3. En rigor, no es que sea compatible, es que la exige. El profesor Romero lo que se pregunta, entonces, es cómo sabe Nietzsche que el mundo carece de sentido, medido según nuestra razón. Pregunta que contiene ya la respuesta de lo que nuestro filósofo propiamente barrunta y nunca abandonaría, por supuesto, la tesis de que mundo y razón humana son inconmensurables. (Algo que a mí se me presenta, por otra parte, simplemente como muestra de pura sensatez a fuer de evidente). Pero a la pregunta de Romero, no obstante, responderemos preguntándole, a nuestra vez, muy extrañados e incluso alarmados, si es que no se ha dado cuenta todavía de que el buen dios ha muerto hace ya tiempo, todo el tiempo que hace que

2 Safranski, R., Nietzsche, biografia de su pensamiento. Barcelona, Tusquets, 2001, p. 49.

3 Op. cit., p. 50. 
se acabó la metafísica. Porque si ocurre lo contrario y el mundo se ajusta a nuestra razón, entonces o bien Descartes tenía razón y Dios existe, o bien Dios no existe, pero recurrimos a la interpretación teleológica u optimista del darwinismo, y con ello salimos del atolladero y el ateísmo deja entonces de ser "difícil". Pero es sabido que Nietzsche se oponía frontalmente a esa interpretación, llevado precisamente de su intuición trágica.

En cuanto al nivel, tan importante para nuestro filósofo, de la verdad acuñada por los intereses vitales de sobrevivir o crecer, lo más interesante del libro que comentamos es, una vez más, ese punto en que se cuestiona la legitimidad gnoseológica de la contraposición nietzscheana de verdad y vida, contradicción que no admitirá componendas de ningún tipo. Aquí interviene Romero de la mano de Franz Hinkelammert, para el que la reproducción de la vida de la especie humana sería el definitivo criterio de verdad con que medir toda formulación intelectual. Es el interés para la vida el que decide en último término. Claro que esto suena muy nietzscheano, pero no lo es, en el fondo, porque la contundencia con la que se afirma le quita todo el espacio a la fundamental verdad trágica. Es cierto que Nietzsche insistía en una época en todo ese tema de que el afán de saber es puro impulso de muerte, diríamos anticipando a Freud. Que la vida juega con la superficie, el espejo, el pliegue, la máscara, acumulando el poder de la mentira.

A mi juicio no hay aquí problema ninguno. No se da oposición de la verdad a la vida humana, porque Dionisos, es decir, el juego agónico de Apolo y Dionisos, lo mismo es el dios de la vida que el dios de la muerte, como nos transmite Heráclito en el Fragmento 15 de la ordenación D.-K. La muerte y la vida son indisolubles en su unión radical, tal es la lección del paganismo griego, y si Nietzsche combate contra el teólogo cristiano es precisamente porque su mentalidad se define esencialmente como empeñada en el demencial ensayo, constitutivo de nuestra cultura enferma, de purgar la vida de la muerte, el bien del mal, al hombre del pecado. Algo que además de imposible sería inconveniente, porque nos llevaría a una paz monstruosa, la perpetua paz del cementerio. No hay vida eterna, no hay vida verdadera, no hay vida más allá del tiempo. La vida baila continuamente con la muerte, o sea, discurre a la deriva en el flujo heraclíteo, y cuando se acaba este baile lo que tenemos es la nada, simple y llanamente. Por eso no constituye problema alguno el de la pretendida contraposición nietzscheana de la terrible verdad dionisíaca y la vida humana: la vida humana tiene un momento esencial que es su momento puramente dionisíaco o mortal de necesidad. Sin que la verdad meramente pragmática estuviera asediada de continuo por la verdad trágica, sus construcciones dejarían inmediatamente de ser útiles y perderían todo su sentido porque se irían a coagular en la ilusión o pseudoverdad metafísica.

En lo referente al aristocratismo, o "elitismo epistemológico" nietzscheano, o sea, la denuncia de que el acceso a la verdad dionisíaca sea patrimonio de unos pocos privilegiados, he de decir que con esto no logro salir de mi asombro. Me imagino que esta denuncia la harán "los de abajo", claro: toda pretendida verdad, para serlo efectivamente, deberá ser públicamente accesible, o sea democrática. Desde esta perspectiva por supuesto que Nietzsche es un reaccionario, sus verdades difícilmente se podrán llevar al mercado donde el dinero de cualquiera es tan bueno como el dinero de cualquiera. Recordaremos que Nietzsche declaraba escribir a propósito con un estilo que mantuviese apartados a los más de esos libros suyos dirigidos a todos y a nadie. No son sus verdades dirigidas al consumo masivo sino a la distinción, y 
toda distinción parece delito. Pero lo que me asombra son dos cosas. Primera, esto ya se sabía por lo menos desde Brandes. Segunda, el mismo Romero apunta de manera muy convincente a la definición de este elitismo epistemológico nietzscheano. Para descubrir ciertas verdades, para tratar con ellas, hace falta valor, mucho valor, y por supuesto no todo el mundo es valiente (¿o vais a decir que sí, que todos somos iguales en este punto?). Para descubrir ciertas verdades, en el caso de Nietzsche, hace falta tener una dilatada experiencia de la enfermedad y del dolor, y no todo el mundo la tiene, indiscutiblemente. ¿Por qué cuesta trabajo admitir que Nietzsche no era normal, no era como la mayoría, que sus capacidades cognitivas, su lucidez, diríamos de un modo menos estúpido, se hallaba por encima de lo que es corriente? ¿Por qué nos parece tan extraño que ciertas personas sean más sabias que otras? ¿No nos lo dice la experiencia de la vida y de la historia? ¿No ha conocido usted a ningún idiota? Yo sí, a varios, incluyéndome a mí mismo en las horas bajas. Negarlo será el efecto del prejuicio de la moral, de la moralina: nos desagrada que las cosas sean así, que sean así desmiente nuestra sensibilidad moral, que es tan fina. Encontramos a menudo que lo esencial no es la naturaleza de la investigación y sus resultados sino las consecuencias ético-políticas de la misma. Y si estas consecuencias parecen "peligrosas", entonces con toda seguridad nos hemos equivocado. Porque solo hay que buscar la verdad para hacer el bien, de lo contrario maldita la falta que nos hace. Como deseamos luchar en contra de la "asimetría social", o al menos dar la impresión de que lo hacemos, o sea, hablar en contra de la tal asimetría, entonces no nos podemos permitir reconocer lo que es evidente, que los hay más o menos idiotas y los hay más o menos sabios, porque si no se insinuaría peligrosamente que la famosa asimetría pudiera tener algún fundamento in re. ¡Y hasta ahí podríamos llegar! (aparte de que no saldríamos en la foto).

\section{III}

Pero la aportación más clara y brillante del libro de Romero discurre en las páginas que dedica a la verdad "en el plano histórico-social", es decir, a la genealogía nietzscheana. No en vano se localiza aquí lo positivo de Nietzsche, su conquista definitiva y como tal llamada a fecundar muy productivamente las principales corrientes del pensamiento contemporáneo. La remisión de todo constructo social a su origen dejaría en evidencia la índole artificial y artificiosa de todo constructo social, sin excepción, arruinando la general aspiración a la indiscutibilidad que es común a todos ellos. En este plano la verdad nietzscheana es la verdad abierta y ofensiva del parresiasta recuperado por Foucault. Pero con todo ello se contradice en primer lugar la disposición del profesor Romero a aceptar sin más la idea, defendida entre otros por Janz, de que en la trayectoria intelectual nietzscheana hay un declive muy pronunciado en los últimos años de su vida lúcida, una decadencia que llegaría a su máxima expresión en obras como Ecce Homo y El Anticristo. Porque es especialmente en estas obras del final en que asistimos al espectáculo edificante del Nietzsche anticristiano que dice la verdad desconsideradamente, con sinceridad brutal rayana en el cinismo. El problema consiste sin duda en que aquí su mensaje sería mínimamente ambiguo, una auténtica llamada al combate, y entonces, a diferencia de lo que ocurre en las obras anteriores, ciertos intérpretes no pueden refugiarse en la estratagema de volver a acoger al Cristianismo, con todos los honores y por la puerta de atrás, por ejemplo como una perspectiva más en el juego de las 
infinitas perspectivas. Por eso nos dicen que en las obras del final no hay matices, no hay complejidad "epistemológica", no hay autocrítica, y el resultado no puede ser sino una caída general del nivel filosófico. Una vez más, la teoría del conocimiento como guardiana de la moral y sus intereses.

Por otra parte, no vendría mal reparar reflexivamente en cómo la verdad genealógica nietzscheana, la que tanto juego daría para todo futuro en las dimensiones éticas y políticas, se ve posibilitada en su núcleo más íntimo precisamente por la intuición de la verdad terrible de Dionisos. El saber que no hay orden ninguno en absoluto, parece sabiduría en todo solidaria con la actividad crítica y genealógica de desmontar la pretensión de todo orden concreto a la indiscutibilidad o a la naturalidad o a la normalidad. Para desmontar un orden injusto hay que saber que todo orden es arbitrario y ninguno totalmente justo. Eso sería lo lúcido por nuestra parte, porque si pensamos que, al contrario, vamos a la búsqueda de UNO que sí lo es, necesario porque justo, uno que es nuestra meta, el fin de la historia, entonces iremos a dar en la metafísica, es decir, en la tiranía pura y simple. Así, cuando el profesor Romero escribe que "lo verdaderamente real en tanto que devenir irracional, desmesura, violencia, es para Nietzsche aquello sobre lo que realmente se asienta la sociedad burguesa, aquello que es incapaz de asimilar e integrar y trata de velar a toda costa" ( $p$. 97), por nuestra parte nos permitiríamos la corrección, respecto de la primera de sus observaciones, de que ese devenir irracional es aquello sobre lo que se asientan todas las sociedades humanas, no solo la burguesa. Aunque está claro que ser consciente de esto no solo no impide luchar por un mundo mejor, sino que alienta la lucha, por lo menos desde el punto de vista trágico que es el nietzscheano. Saber que no hay una solución que sea definitiva es lo que moviliza la lucha de la vida. Tal vez la intuición trágica del mundo resulte naíf, pero a mí me parece más naíf pensar en una abolición (definitiva) de la explotación como punto culminante y final de la historia humana. Recordemos al Freud de la pulsión de muerte y sus comentarios sobre la inocencia antropológica de los comunistas en El malestar de la cultura. Al fin y al cabo, la revolución no deja de ser un juicio final inmanente, sus ideales parecen algo infantiles en consecuencia, sin referirnos ahora al asunto del resentimiento.

Una limitación del libro de Romero, que también podría explicar que se enrede en cuestiones como las referidas, sería la elusión consciente del asunto del Übermensch, "porque se refiere al futuro, no al presente" y en ese sentido es figura utópica. Pero sin duda la del superhombre es cuestión crucial para el mismo planteamiento de la verdad nietzscheana. El humano no tiene arreglo, por eso tiene que ser superado. Si fuera cierto que la explotación es el hecho fundamental de toda historia, sin duda tendríamos que entender aquí la historia humana, y en absoluto me parece que una mirada desprejuiciada fuera a contradecir esta afirmación. El hombre es una cuerda tendida entre animal y Übermensch, de manera que no podemos pensarlo como algo fijo, estable, definitivo. Por eso cabría objetar a Romero que al no tomar en consideración el tema del superhombre no está haciendo crítica inmanente, sino que se aplica a la tarea de medir el pensamiento de Nietzsche con criterios que parecen cristiano-marxianos, en definitiva nada nietzscheanos.

Este carácter externo o trascendente de la crítica de Romero estaría justificado y sería perfectamente legítimo, no en menor medida porque la sensibilidad del autor 
no es en el fondo nietzscheana. Esta idea se me confirmó al darme cuenta del papel fundamental que en el libro desempeña el diálogo con Hinkelammert, teólogo de la liberación. Este pensador alemán, que continuará su trabajo intelectual en Chile y Costa Rica, habría cumplido catorce años cuando la derrota del nazismo. Más adelante, al tiempo que leía a Nietzsche subían a su conciencia los recuerdos de las consignas que los nazis usaban de estos textos, aislados y sin citarlos. Por eso Hinkelammert sometió a una dura crítica al filósofo alemán, pero por otra parte supo utilizar aspectos de su filosofía con un propósito liberador. De alguna manera hizo lo que el profesor Romero quiere hacer en su libro: pensar con Nietzsche contra Nietzsche, o mostrarnos qué aspectos de su pensamiento contradicen a qué otros, y por tanto no pueden ser mantenidos simplemente utilizando un criterio interno.

El asunto de Nietzsche y los nazis se me hace sobremanera fastidioso. Darse cuenta de cómo pudo ser que le utilizaran en algunos aspectos viene siempre de la mano con hacerse consciente de que en todo momento fue utilizado, en el sentido de falsificado en tanto sometido a objetivos que en absoluto eran los suyos. Por otra parte, se percata uno del maltrato a que fue sometido Nietzsche, una de las víctimas del nazismo, en su momento y para el futuro. Por eso me parece mentira que el mencionado teólogo de la liberación no viera, cuando adulto y en su madurez, que los nazis no pudieron recoger un pensamiento como el de Nietzsche entre sus propias "ideas", ni mucho menos ajustarlo a lo que podríamos llamar la filosofía del eslogan característica de la propaganda política. Hubiera sido de todo punto imposible, y eso que hoy estamos bastante hechos a la filosofía como propaganda, comercial y política; sin tener que detenernos aquí en el señalamiento del antinacionalismo, el antigermanismo y el anti-antisemitismo tan evidentes de Nietzsche. "Si los nazis hubiesen leído de verdad a Nietzsche, habrían quemado sus libros", indicó D'Iorio en un medio de comunicación español no hace mucho.

No cae Romero en este error que habría sido de bulto, sino que en su denuncia del supuesto Nietzsche nazi corrige a Hinkelammert, y se propone rescatar a Nietzsche de sí mismo. Pero no sé si de verdad hará falta, una vez comprendido el corazón de la transvaloración. Porque la lección de la Umwertung nietzscheana, por repetirla, es que no hay oposición de lo blanco y lo negro, sino que están en los extremos de una escala de grises; pero, sobre todo, que blanco y negro se condicionan mutuamente en su misma posibilidad. Ya lo vimos, Dionisos y Hades son el mismo dios, el de la vida y el de la muerte. Por eso no se puede seguir actuando como hemos venido actuando siempre, demonizando nuestra "parte maldita", aplastándola, eliminándola, porque son los árboles de raíces más profundas los que más alto llegan en el cielo con sus ramas. La altura depende de la profundidad, el bien del mal, esa es la lección de Nietzsche, de manera que no se puede separar al Nietzsche blanco del negro porque entonces sencillamente nos lo cargamos, le castramos, lo convertimos en un santo. Justo lo que le horrorizaba.

Estamos ante un libro honesto, sabio, magníficamente documentado, pero la sensibilidad que pone en juego no me parece apta para conectar con el espíritu nietzscheano en lo que lo hace más auténtico, su intratabilidad de fondo, justamente aquello en que el alemán no es un filósofo como otro cualquiera de los grandes. Por lo mismo, sí que sería útil para separar en Nietzsche lo blanco de lo negro desde un criterio sin duda externo. 